Research Article

\title{
Electric Conductivity and Piezoresistivity of Carbon Nanotube Artificial Skin Based on the Design of Mesh Structure
}

\author{
Xin Ma ${ }^{D},{ }^{1}$ Wen Li, ${ }^{1}$ Liting Wang, ${ }^{1}$ and Xiaona $\mathrm{Cao}^{2}$ \\ ${ }^{1}$ School of Computer Science and Software Engineering, Tianjin Polytechnic University, Tianjin, China \\ ${ }^{2}$ School of Nursing, Tianjin Medical University, Tianjin, China \\ Correspondence should be addressed to Xin Ma; mxtjcn@126.com
}

Received 19 October 2017; Accepted 20 March 2018; Published 30 April 2018

Academic Editor: Ana María Díez-Pascual

Copyright ( 12018 Xin Ma et al. This is an open access article distributed under the Creative Commons Attribution License, which permits unrestricted use, distribution, and reproduction in any medium, provided the original work is properly cited.

This paper introduces a new method of sensing pressure by using carbon nanotube yarns which are embedded in artificial skin, based on the design of the mesh structure. With the sensing technology, a kind of mesh model has been established for piezoresistive effect detection of carbon nanotube yarns in artificial skin. By analyzing the sensing characteristics of carbon nanotube yarns, we can conclude that the artificial skin embedded with yarns in a mesh model could be used for sensing pressure. It may cover the surface of the robot and has significant theoretical as well as practical value for intelligent robot research in the future.

\section{Introduction}

With the development of AI, intelligent robots have gradually come into people's lives. More and more advanced technology requires the robots to possess the ability of perception [1]. It is of vital importance to make artificial skin have the function of perception. The artificial skin [2], large and soft, covering the robots, has the ability of data processing. And it can sense the outer environment and the relevant circuit on the basis of an embedded sensor array [3] in the skin.

Nowadays, the carbon nanotube artificial skin is a kind of material which is filled with a certain amount of carbon nanotubes acting as a sensor array to sensing tactile [4]. When there is an impact on the skin material, robots can do dynamic signal tests and analyses by using artificial skin and then get the response to external impact signal and tactile perception of the outside world.

This kind of artificial skin sensor has the advantages of low cost, simple structure, fast response, high sensitivity, and so on [5]. It can be used in the robots to grab objects nondestructively. And it would be of some theoretical and practical significance for improving the intelligence of the robot [6].

In this work, we report a kind of artificial skin of carbon nanotube lines/silicone polymer. It can feel the environment by embedding the carbon nanotubes and relevant circuits in artificial skin. The paper has specifically introduced the design method of artificial skin, signal processing, mesh models, and get the state expression. We also explore the relationship between quantity and resistivity, the relationship between quality and resistivity of carbon nanotubes, and piezoresistive effect under different qualities of the same carbon nanotubes.

\section{Materials and Methods}

The carbon nanotube lines have high toughness, good pressure-sensitive properties, and excellent electrical and thermal properties [7]. After combining with the silica gel, the performance of the composite material can be greatly improved which could be used to produce artificial skin material of high quality. The carbon nanotubes used in this experiment are carbon nanotubes of NF800, NF1000, and NF1200 which are produced by Beijing BOYU GAOKE new material technology company.

The kind of piezoresistive pressure sensors [8] has recently attracted attention due to their facile interaction with artificial skin and monitoring capabilities [9]. It has lots of advantages, such as simplicity of design, fast response, easy signal detection, scalability, and low-cost fabrication. 


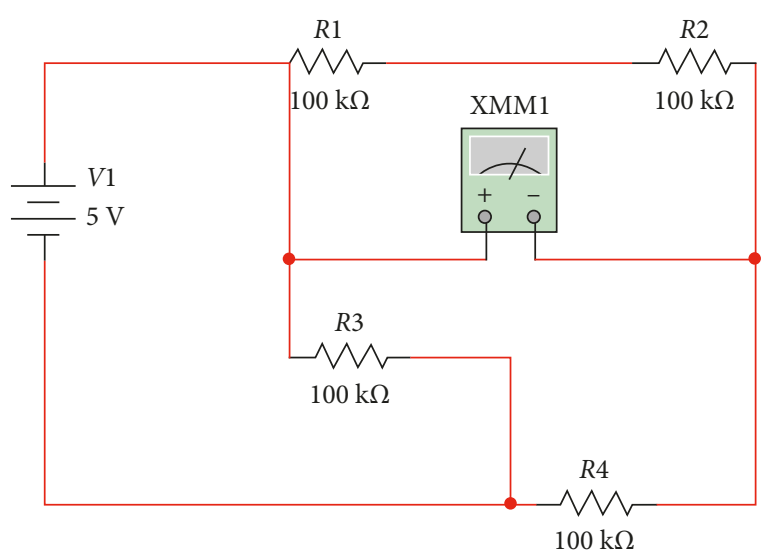

Figure 1: The three wires method.

In addition, the sensor array based on piezoresistivity can detect not only the position signal but also the pressure signal at the same time.

However, this method has some limitations, which means it is difficult to determine the specific location of the impact or collision. In order to overcome this problem, we designed the artificial skin of carbon nanotube [10] lines based on mesh models. We put the carbon nanolines in a crisscross shape, like a coordinate axis, and connect the measuring instruments to the end of every nanolines. When there is an impact on the mesh models, intersection points can feel the pressure, leading to the current change of each carbon nanolines at the points, and then the rate of resistivity change is measured.

Now the material of artificial skin is mainly made from full leather, rubber, silk, chitosan, collagen protein, and so on. For real-time monitoring of the signal changes of the robot skin, silica gel is insoluble in water or any solvent. Nontoxic, tasteless, good chemical stability, high hardness, and the tensile strength are similar to the real skin of the human body [11]. It is easier to embed carbon nanotubes into it. So, we use silica gel as the main material of artificial skin.

Combining the advantages of carbon nanotube lines with lightweight, good mechanical properties and electrical and chemical stability [12], we also designed carbon nanotube lines/silicone polymer of the artificial skin tactile sensor based on mesh models.

We embedded the carbon nanotube lines into the silica gel polymer to form the mesh model, so this kind of artificial skin could transfer the strain [13] source to the sensor network; therefore, the skin can get the information promptly.

Piezoresistive mechanism, strain-responsive mechanism, and disconnection mechanism [9] are included in this kind of artificial skin.

This piezoresistive effect refers to the energy change caused by the silica gel under the influence of pressure, resulting in the change of electrical resistivity.

Stretching of thin films leads the connected nanomaterials to reduce their overlapped area and electrical connection and then increases the electrical resistance.

In summary, the advantages of carbon nanotubes are high linearity and stretchability [9].

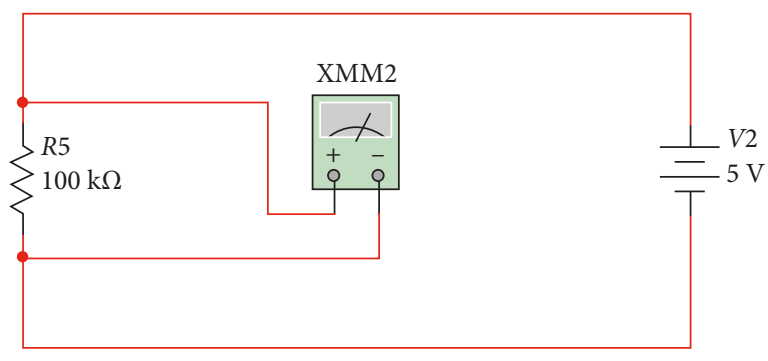

Figure 2: The four wires method.

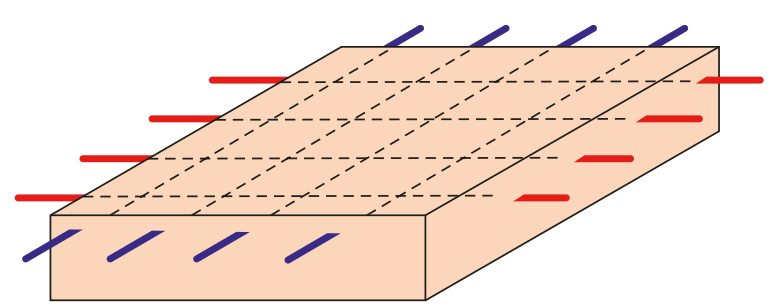

FIGURE 3: Flat mesh macrostructure of the carbon nanotube line.

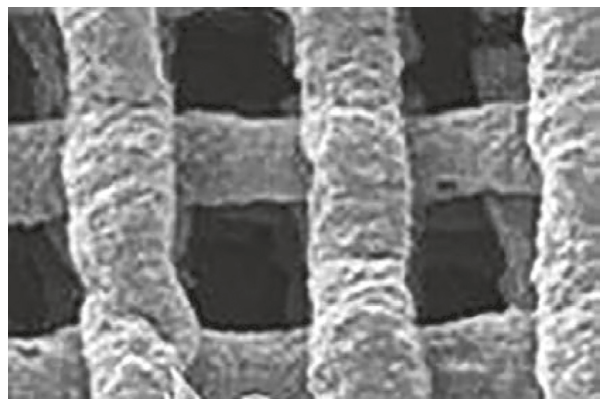

Figure 4: Flat mesh microstructure of the carbon nanotube line.

In order to measure the current changes of the carbon nanolines, we used two main methods to detect this. We considered the carbon nanolines as resistors by analogy and reduced the errors as much as possible to ensure the measured accuracy.

The methods of circuit connection are different and also can make the result of measurement differ greatly. To reduce the deviation, we can use three wires or four wires method. Using three wires or four wires to measure the circuit, it is necessary to connect wires with the root of the carbon nanolines; otherwise, there will be deviations.

In the three wires method, one end of the root of the resistor is connected with a lead wire, and the other end is connected with two lead wires, hence called the three wires system. The connection method is shown in Figure 1, and this method can eliminate the influence of lead resistance.

In the four wires method, two wires are connected with both ends of the resistance root. The connection mode is shown in Figure 2, and this method can completely eliminate the influence of lead resistance.

2.1. Carbon Nanotube Yarn Embedded Method. First of all, we made the carbon nanotube line a cross to form a flat mesh structure, as is shown in Figures 3 and 4, and each row and 
Table 1: Parameter configuration of the samples.

\begin{tabular}{|c|c|c|c|c|c|c|c|c|}
\hline $\begin{array}{l}\text { Sample } \\
\text { number }\end{array}$ & $\begin{array}{c}\text { Number of } \\
\text { carbon nanotube } \\
\text { line }\end{array}$ & $\begin{array}{c}\text { Density of } \\
\text { carbon nanotube } \\
\text { line }\end{array}$ & $\begin{array}{c}\text { Diameter of } \\
\text { carbon nanotube } \\
\text { line }\end{array}$ & $\begin{array}{c}\text { Strength of } \\
\text { carbon nanotube } \\
\text { line }\end{array}$ & $\begin{array}{c}\text { Elongation } \\
\text { at break }\end{array}$ & Conductivity & $\begin{array}{c}\text { Pipe } \\
\text { diameter } \\
(\mathrm{nm})\end{array}$ & $\begin{array}{l}\text { Aspect } \\
\text { ratio }\end{array}$ \\
\hline G1 & CNTL1 & $0.3 \mathrm{~g} / \mathrm{cm}^{3}$ & $12 \mu \mathrm{m}$ & $300 \mathrm{MPa}$ & & $5 \times 10^{4} \mathrm{~S} / \mathrm{m}$ & $20-30$ & 500 \\
\hline $\mathrm{G} 2$ & CNTL2 & $.5 \mathrm{~g} / \mathrm{cm}^{3}$ & $12 \mu \mathrm{m}$ & $800 \mathrm{MPa}$ & $2 \sim 3.5 \%$ & $5.3 \times 10^{4} \mathrm{~S} / \mathrm{m}$ & 20 & $300-500$ \\
\hline G3 & CNTL3 & $0.8 \mathrm{~g} / \mathrm{cm}^{3}$ & $12 \mu \mathrm{m}$ & $1000 \mathrm{MPa}$ & $2 \sim 3.5 \%$ & $6 \times 10^{4} \mathrm{~S} / \mathrm{m}$ & $20-30$ & $300-500$ \\
\hline G4 & CNTL4 & $1.0 \mathrm{~g} / \mathrm{cm}^{3}$ & $12 \mu \mathrm{m}$ & $1200 \mathrm{MPa}$ & $2.5 \sim 3.5 \%$ & $7.1 \times 10^{4} \mathrm{~S} / \mathrm{m}$ & $20-30$ & $300-500$ \\
\hline
\end{tabular}

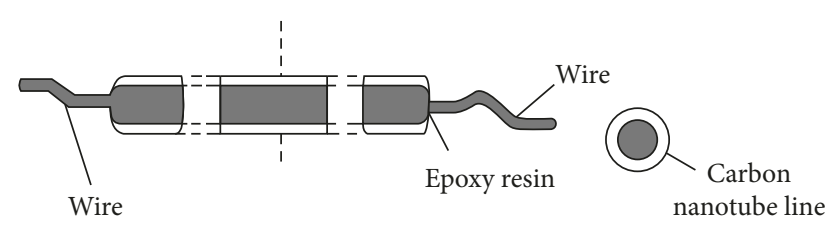

FIGURE 5: Interface with stitches of the carbon nanotube line.

column are spaced. The smaller the spacing, the greater the density of the mesh, and hence, the sensitivity of perception of outside environment is higher. Secondly, we put this mesh structure into a mold whose bottom is square and the side is rectangular with some holes and then poured the liquid silica gel into it, and finally it was solidified at about 56 seconds at high temperature of $150-160^{\circ} \mathrm{C}$.

The thickness of artificial skin is $1.7 \mathrm{~mm}$, and the length of the side is $2.4 \mathrm{~cm}$. We used four kinds of carbon nanotube lines to embed in the silica gel [14] artificial skin, and the length of each line is $2.4 \mathrm{~cm}$ (same as the length of the side of artificial skin). So we got 4 groups of different samples. The number of carbon nanotube lines of each group is different. They are $3 \times 3,4 \times 5,6 \times 6,8 \times 8$, and $10 \times 10$. The parameters of the samples are shown in Table 1 .

2.2. Signal Processing of Artificial Skin. As is shown in Figure 5, the two ends of each carbon nanotube in the artificial skin are connected with the stitches [15]. When the interface [16] was connected to an analog-to-digital converter, the current [17] would continuously change from analog signal to digital signal, and then access MCU. MCU can identify the current digital signal after conversion and analyze the resistance change rate of each carbon nanotube line. Based on the analysis of the state of each carbon nanotube in the grid, we established the perception model and then calculated the coordinate location of the artificial skin when the external impact or collision occurs.

2.3. Perception Model of Artificial Skin. According to the flat mesh structure of carbon nanotube lines (shown in Figure 3) and the design of the algorithm, the state expression of the flat mesh structure we defined is as follows:

$$
L\left(X=\frac{x}{Y}=y, T=t, R^{\prime}=\frac{\Delta R}{R_{0}}\right),
$$

where $L$ represents one of the carbon nanotube lines in the mesh structure and $x / Y$ is the number of carbon nanotube lines of the horizontal plane from left to right or vertically

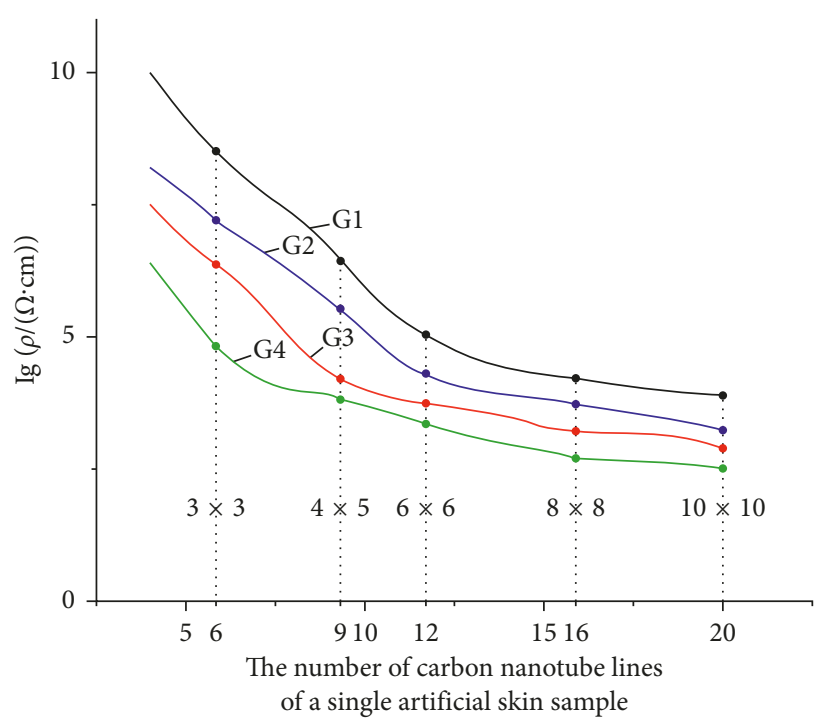

FIGURE 6: Relationship between quantity and resistivity of a single artificial skin sample.

from bottom to top which starts from 0 . The parameter $T$ stands for time and $R^{\prime}$ stands for the moment that line $L$ gets force or stress wave. The change of resistance rate can reflect the fluctuation degree of the stress on the artificial skin. The expression of the mesh structure's intersection point can be extended by the following content:

$$
P\left(X=x, Y=y, T=t, R_{x}^{\prime}=\frac{\Delta R_{x}}{R_{x 0}}, R_{y}^{\prime}=\frac{\Delta R_{y}}{R_{y 0}}\right) .
$$

where $P$ represents a node in the mesh structure and parameters $R_{x}^{\prime}$ and $R_{y}^{\prime}$, respectively, represent $X$ and $Y$ in the direction of stress or stress wave of the carbon nanotube line in the moment. The sequence number of $x$ and $y$ is the occurrence of the carbon nanotube line resistance change rate.

For this perceptual model, we can visualize the whole grid and create an intuitive map for outputting a picture which is similar to the infrared imaging. The color of the carbon nanotube line which is not deformed is black. $R^{\prime}$ changes ranging from zero to infinite. Using the shades of color to represent the variation range of $R^{\prime}$, we can directly find the fault point or area where the position of the coordinates should be, and the darker place is near the location of the stress [18] source.

\section{Results and Discussion}

Figure 6 shows the curve that represents the relation between the carbon nanotube lines and the silica gel skin's resistivity 


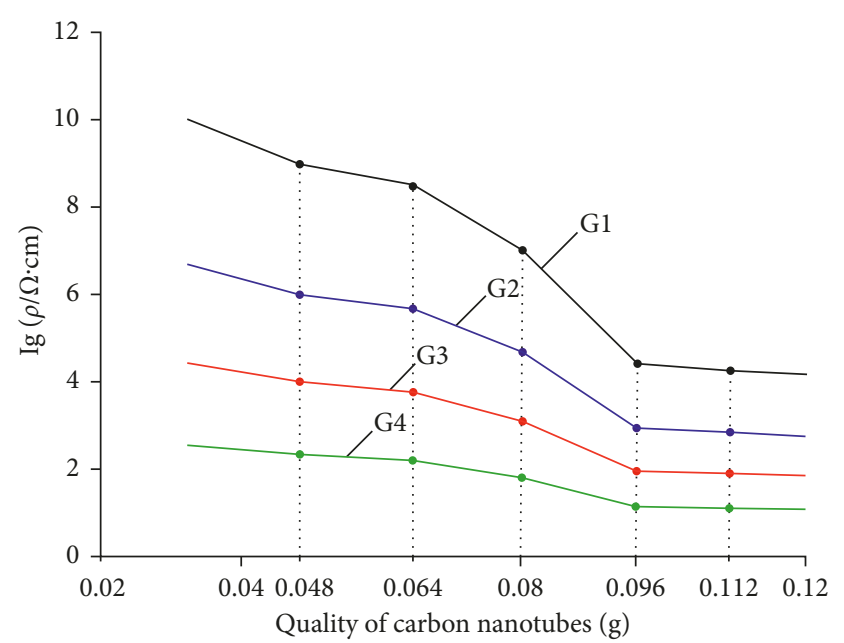

FIGURE 7: Relationship between quality and resistivity of carbon nanotubes.

[19] of artificial skin samples of G1, G2, G3, and G4 groups. It can be seen from the figure that the resistivity of the four kinds of nanolines decreases with the increase of the number of carbon nanotube lines. The increase of the number of carbon nanotube lines has significantly improved the electrical conductivity of artificial skin. Meanwhile, for all artificial skin samples, when the number of carbon nanotube lines is same, their resistivity would decrease because the density increases. For example, in Figure 6, when the number of carbon nanotube lines is 6, the density of the G1 sample is $0.3 \mathrm{~g} / \mathrm{cm}^{3}$ and the $\mathrm{G} 4$ sample is $1.0 \mathrm{~g} / \mathrm{cm}^{3}$. So, the resistivity of the G1 sample is the highest and that of the G4 sample is the lowest.

We can figure out the quality of each carbon nanotube line from Table 1, which shows the density of the carbon nanotube line and the diameter of the carbon nanotube line. As the 4 kinds of carbon nanotube lines we used are at the same length of $2.4 \mathrm{~cm}$, the carbon nanotubes are evenly distributed [20] in the silica gel. So, the more the number of carbon nanotube lines, the heavier the quality of carbon nanotubes. We used G2's quality of the carbon nanotube line as benchmarks. G2's qualities of carbon nanotube lines are $0.048 \mathrm{~g}(3 \times 3), 0.064 \mathrm{~g}(4 \times 5), 0.080 \mathrm{~g}(6 \times 6)$, and $0.112 \mathrm{~g}$ $(10 \times 10)$. And then, according to the above benchmarks, we found the relationship between the same quality and resistivity of different carbon nanotubes.

As is shown in Figure 7, when the single sample is filled with less carbon nanotube lines, the resistivity is significantly high. With the increasing number of carbon nanotube lines, all the nanotube lines are overlapped and formed conductive grids, and the conductive ability comes from these grids, so the resistivity drops to a minimum. As a result of the different density of the four samples, G4 has the lowest resistivity, for it has the highest density of carbon nanotubes. On the contrary, G1 has the highest resistivity because of the lowest density of carbon nanotubes.

The key to make the superior pressure-sensitive devices is the pressure-resistance characteristics. The experiment has tested the relation between the pressure $\mathrm{F}$ and the resistance

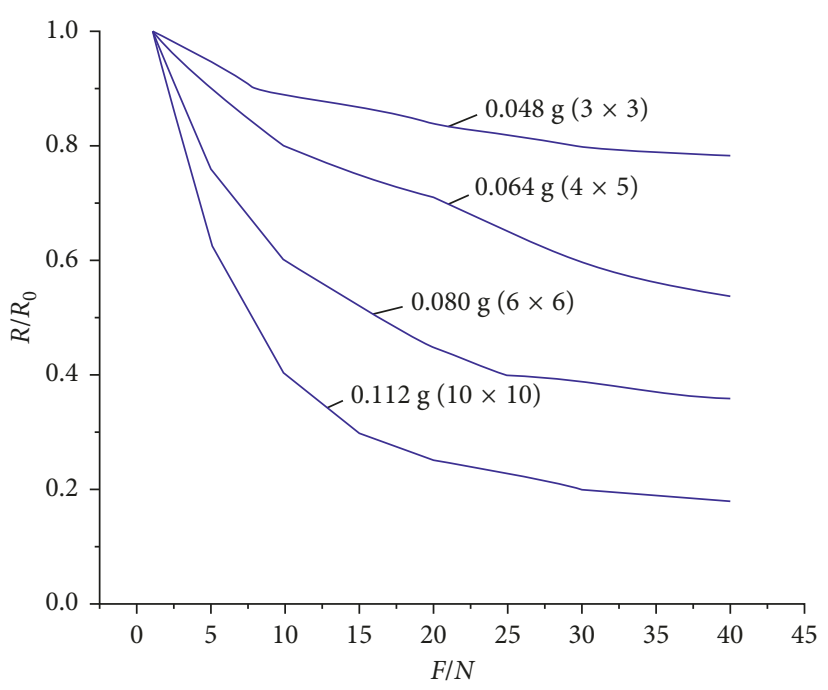

FIGURE 8: Pressure-resistance characteristics under different qualities of the same carbon nanotubes.

relative change $R / R_{0}$ ( $R$ is the resistance after being stressed, and $R_{0}$ is the original resistance) in different qualities $(0.048 \mathrm{~g}(3 \times 3), 0.064 \mathrm{~g}(4 \times 5), 0.080 \mathrm{~g}(6 \times 6)$, and $0.112 \mathrm{~g}$ $(10 \times 10))$ of the same sample of G2. The result is shown in Figure 8.

Looking at Figure 8 , we can find out that when the pressure [21] is fixed, a single skin sample filled with $3 \times 3$ carbon nanotube lines ( $0.048 \mathrm{~g}$ carbon nanotubes) has small variations in resistance as a result of this number of carbon nanotube lines, the spacing between lines is larger, grid density of conductive network is smaller, and the decrease of resistance is limited. With the increasing number of nanolines, conductive mesh's density would increase; thus, the conductive path increases gradually, and the resistance steadily decreases. With the further increase of pressure, the number of conducting channels reaches the limit, the resistance's change tends to be stable, and the sensitivity would decrease.

\section{Conclusion}

This paper is focused on carbon nanotubes/silica gel composites for artificial skin. The experiment explored the relationship between quantity and resistivity, the relationship between quality and resistivity of carbon nanotubes, and pressure-resistance characteristics under different qualities of the same carbon nanotubes. The experiment shows that the higher the number of carbon nanotube lines, the lower the electrical resistivity of the skin, and the skin resistivity decreases with the increase of the density of carbon nanotubes. Under the lower filling quality, the electrical resistivity of the skin is higher. With the increase of the filling quality, the electrical resistance of the skin decreases gradually and finally tends to be stable. The piezoresistive [22] properties of the skin is mainly affected by the number of carbon nanotube lines; the higher the number of filling, the greater the density of the conductive grid, and the greater the change of resistance; the resistance change tends to be stable when 
the number of conductive channels reaches the limit. Therefore, the artificial skin material can be covered on the surface of the robot, sensing the external environment and processing the data according to the sensor array.

\section{Conflicts of Interest}

The authors declare that they have no conflicts of interest.

\section{References}

[1] P. Dario and G. Buttazzo, "An anthropomorphic robot finger for investigating artificial tactile perception," International Robotics Research, vol. 6, no. 3, pp. 25-47, 1987.

[2] M. Park, M.-S. Kim, Y.-K. Park, and J.-H. Ahn, "Si membrane based tactile sensor with active matrix circuitry for artificial skin applications," Applied Physics Letters, vol. 106, no. 4, 2015.

[3] X. Li, W. Huang, and G. Yao, "Highly sensitive flexible tactile sensors based on microstructured multiwall carbon nanotube arrays," Scripta Materialia, vol. 129, pp. 61-64, 2017.

[4] S. H. Park, S. Y. Kim, J. H. Kim, and I. Kang, "Carbon nano artificial neuron system for flexible tactile sensing," in Proceedings of 10th International Conference on Ubiquitous Robots and Ambient Intelligence (URAI), Jeju, Republic of Korea, 2013.

[5] M. Amjadi, M. Turan, C. P. Clementson, and M. Sitti, "Parallel microcracks-based ultrasensitive and highly stretchable strain sensors," ACS Applied Materials and Interfaces, vol. 8, no. 8, pp. 5618-5626, 2016.

[6] I.-J. Cho, H.-K. Lee, S.-I. Chang, and E. Yoon, "Compliant ultrasound proximity sensor for the safe operation of human friendly robots integrated with tactile sensing capability," Journal of Electrical Engineering and Technology, vol. 12, no. 1, pp. 310-316, 2017.

[7] N. Illy, S. Benyahya, N. Durand et al., "The influence of formulation and processing parameters on the thermal properties of a chitosan - epoxy prepolymer system," Polymer International, vol. 63, no. 3, pp. 420-426, 2014.

[8] D. Lee, H. Lee, Y. Jeong, Y. Ahn, G. Nam, and Y. Lee, "Highly sensitive, transparent, and durable pressure sensors based on sea-urchin shaped metal nanoparticles," Advanced Materials, vol. 28, no. 42, pp. 9364-9369, 2016.

[9] X. Ma, Y. Dong, and R. Li, "Monitoring technology in composites using carbon nanotube yarns based on piezoresistivity," Materials Letters, vol. 188, pp. 45-47, 2017.

[10] J.-W. Han, B. Kim, J. Li, and M. Meyyappan, "Flexible, compressible, hydrophobic, floatable, and conductive carbon nanotube-polymer sponge," Applied Physics Letters, vol. 102, no. 5, 2013.

[11] S. Young Kim, S. Park, H. Wool Park, and D. Hwan Kim, "Sensors: highly sensitive and multimodal all-carbon skin sensors capable of simultaneously detecting tactile and biological stimuli," Advanced Materials, vol. 27, no. 28, pp. 4178-4185, 2015.

[12] M. Amjadi, A. Pichitpajongkit, S. Lee, S. Ryu, and I. Park, "Highly stretchable and sensitive strain sensor based on silver nanowireelastomer nanocomposite," ACS Nano, vol. 8, no. 5, pp. 5154-5163, 2014.

[13] X. Cao, X. Wei, G. Li et al., "Strain sensing behaviors of epoxy nanocomposites with carbon nanotubes under cyclic deformation," Polymer, vol. 112, no. 1-9, 2017.

[14] X. Guo, Y. Huang, X. Cai et al., "Capacitive wearable tactile sensor based on smart textile substrate with carbon black/ silicone rubber composite dielectric," Measurement Science and Technology, vol. 28, no. 4, pp. 40-49, 2017.
[15] M. Shimojo, A. Namiki, M. Ishikawa, R. Makino, and K. Mabuchi, "A tactile sensor sheet using pressure conductive rubber with electrical-wires stitched method," IEEE Sensors Journal, vol. 5, no. 4, pp. 589-596, 2004.

[16] J. Chen, X. Cui, Y. Zhu, W. Jiang, and K. Sui, "Design of superior conductive polymer composite with precisely controlling carbon nanotubes at the interface of a co-continuous polymer blend via a balance of pi-pi interactions and dipoledipole interactions," Carbon, vol. 114, pp. 441-448, 2017.

[17] Y.-B. Kim and K. K. Kim, "Sensor circuit design using carbon nanotube FET for artificial skin," Journal of the Korea Society Industrial Information System, vol. 19, no. 3, pp. 41-48, 2014.

[18] C. N. Xu, T. Watanabe, M. Akiyama, and X. G. Zheng, "Artificial skin to sense mechanical stress by visible light emission," Applied Physics Letters, vol. 74, no. 9, pp. 12361238, 1999.

[19] S. Pralgauskaitè, J. Matukas, M. Tretjak et al., "Resistivity and low-frequency noise characteristics of epoxy-carbon composites," Journal of Applied Physics, vol. 121, no. 11, p. 114303, 2017.

[20] P. Nie, M.-Z. Gao, X.-J. Zheng, and L. Ksenia, "Evaluation method of carbon nanotubes film's uniformity based on information dimension," Journal of Shenyang Aerospace University, vol. 31, pp. 2095-1248, 2014.

[21] H.-M. So, J. W. Sim, J. Kwon, J. Yun, S. Baik, and W. S. Chang, "Carbon nanotube based pressure sensor for flexible electronics," Materials Research Bulletin, vol. 48, no. 12, 2013.

[22] J.-J. Wang, C.-E. Lu, J.-L. Huang, R. Chen, and W. Fang, "Nanocomposite rubber elastomer with piezoresistive detection for flexible tactile sense application," in Proceedings of 2017 IEEE 30th International Conference on Micro-Electro-Mechanical Systems (MEMS), pp. 22-26, Las Vegas, NV, USA, 2017. 


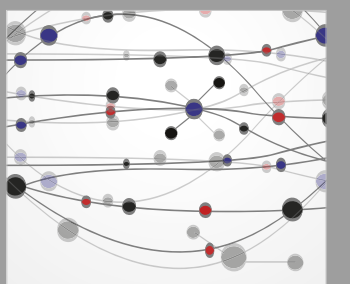

The Scientific World Journal
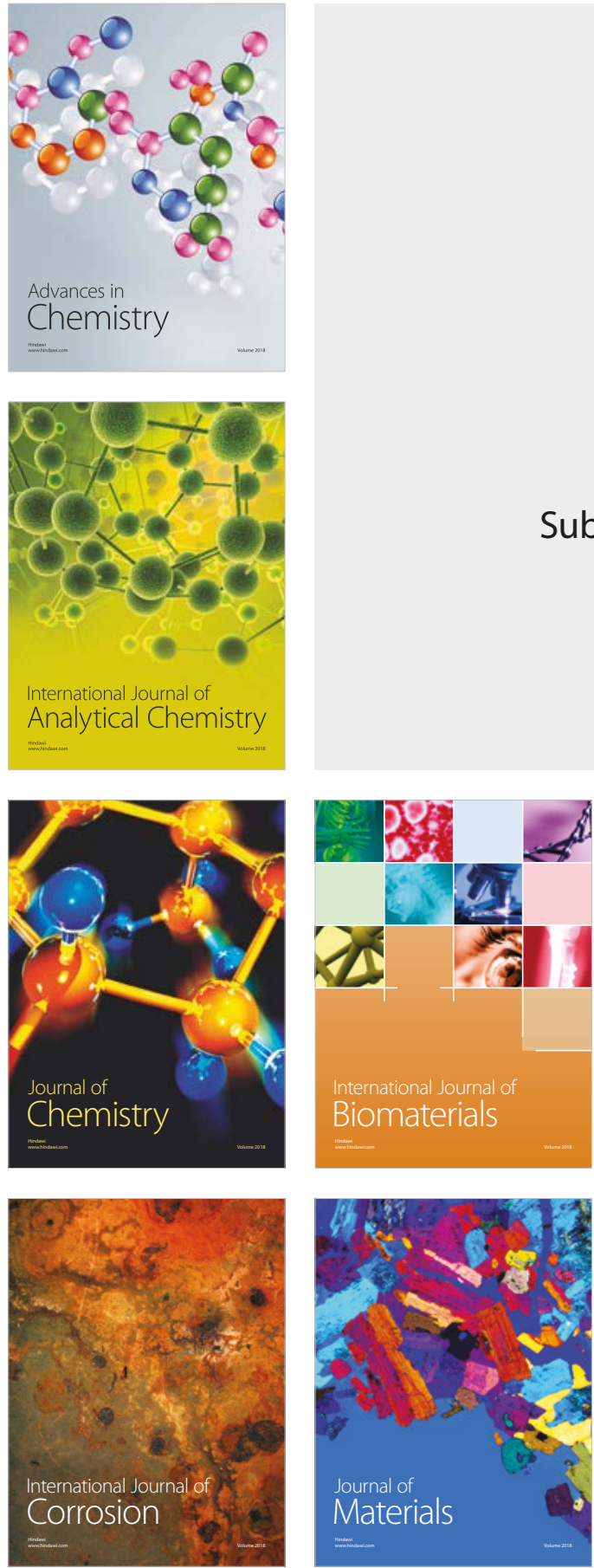

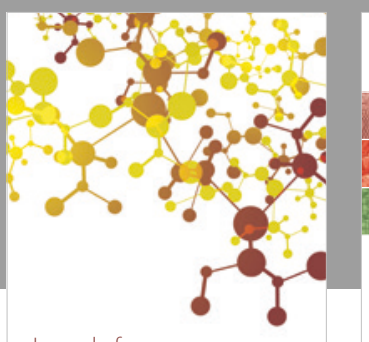

Journal of

Applied Chemistry
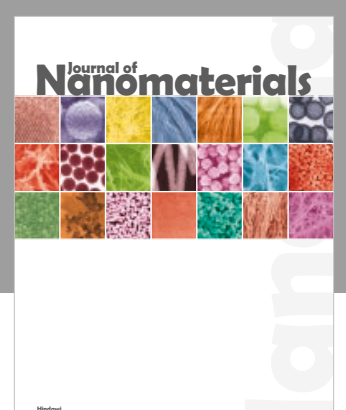

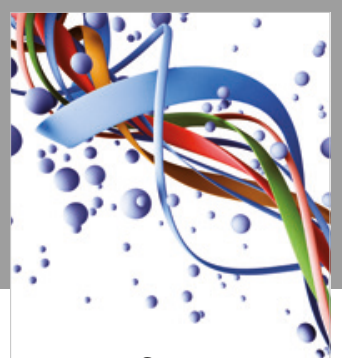

Scientifica

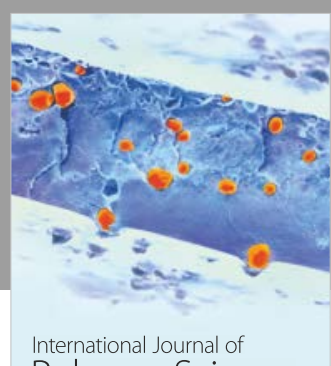

Polymer Science

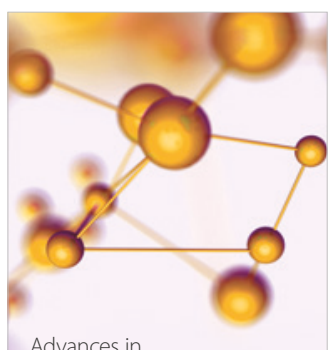

Physical Chemistry
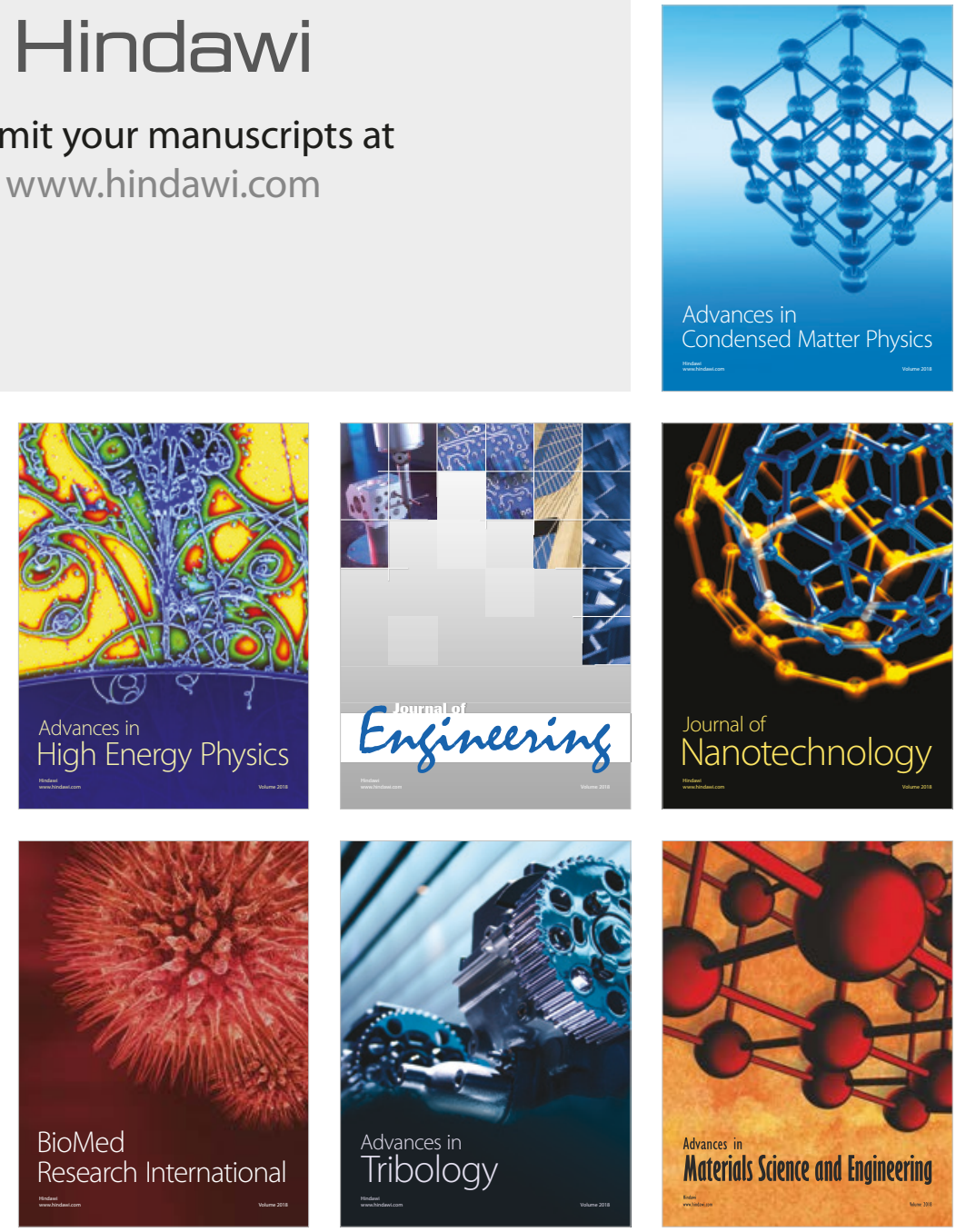